\title{
The emergence of Urban Community Resilience Initiatives During the COVID-19 Pandemic: An International Exploratory Study
}

\author{
Jan Fransen ${ }^{1}$ (D) Daniela Ochoa Peralta ${ }^{2}$. Francesca Vanelli ${ }^{3}$. \\ Jurian Edelenbos ${ }^{4} \cdot$ Beatriz Calzada Olvera $^{5}$ \\ Accepted: 4 December 2020 / Published online: 12 January 2021 \\ (c) European Association of Development Research and Training Institutes (EADI) 2021
}

\begin{abstract}
All over the world, urban communities take initiative in order to cope with the COVID-19 pandemic. This study conducts a literature review and an international exploratory study in order to identify pathways within which Community Resilience Initiatives (CRIs) emerge within different governance contexts. The CRIs target vulnerable communities, which are hard to reach. Our study results identify four pathways: (1) informal bottom-up community initiatives; (2) formal community initiatives emerging out of existing community-based initiatives; (3) initiatives of external actors, often NGOs, universities or governments and (4) networks of organisations whom together initiate action in response to COVID-19. The pathways lead to different types, scales and complexities of the initiatives. However, all face similar barriers related to funding, weak networks and limited cooperation. CRIs often perceive the government agencies to be unreliable and unsupportive which in turn also hampers CRI's emergence.
\end{abstract}

Keywords COVID-19 - Community resilience · Community-based initiatives . Community resilience initiatives · Urban governance

\section{Resumé}

Partout dans le monde, les communautés urbaines prennent des initiatives pour faire face à la pandémie de COVID-19. Cette étude mène une revue de la littérature et une étude exploratoire internationale afin d'identifier les voies par lesquelles les initiatives de résilience communautaire (IRC) émergent dans différents contextes de gouvernance. Les IRC ciblent les communautés vulnérables, qui sont difficiles à atteindre. Les résultats de notre étude identifient quatre voies: (1) les initiatives communautaires informelles ascendantes; (2) les initiatives communautaires formelles issues d'initiatives communautaires pré-existantes; (3) les initiatives d'acteurs ex-

Jan Fransen

J.fransen@ihs.nl

Extended author information available on the last page of the article

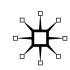


ternes, souvent des ONG, des universités ou des gouvernements; et (4) les réseaux d'organisations qui, ensemble, entreprennent des actions en réponse à la COVID-19. Ces voies mènent à des initiatives de type, d'échelle et de niveaux de complexité différents. Cependant, elles sont toutes confrontées à des obstacles similaires liés au financement, à la faiblesse des réseaux et à une collaboration limitée. Les IRC perçoivent souvent les agences gouvernementales comme étant peu fiables et peu sources de soutien, ce qui freine également l'émergence du CRI.

\section{Introduction}

The COVID-19 pandemic constitutes a global health shock, with a death toll of over one million and over 33 million people reported ill by 1 October 2020 (WHO 2020). The measures taken for its control and mitigation have added a socio-economic shock, threatening the livelihoods of people around the world (Kenny 2020). Community resilience can play a major role in coping with shocks (Magis 2010). However, it is an ambiguous concept, hard to define and measure (Zamboni 2017). We define it as a complex and dialogical process in which communities create, develop and/or engage their resources to cope with shocks and its consequent uncertainty (Magis 2010; McCrea et al. 2014).

In this article, we focus on the emergence of urban Community Resilience Initiatives (CRIs) in the initial recovery stage of the COVID-19 pandemic. Urban communities are likely to be both more vulnerable and more capacitated and networked than rural communities in coping with a health shock due to the relatively high density and proximity of services, actors and resources (Alonge et al. 2019; Nicola et al. 2020). In the period of April-August 2020, many urban CRIs have emerged within a context of overwhelmed (health) services, semi-closed economies and a related shortage of services, protective materials and jobs. During this stage of the health crisis, CRIs are likely to support communities to adapt, that is: to continue its 'normal' functioning to the extent possible. In other stages of community resilience, which we do not study in this article, CRIs may also enable communities to prepare for a crisis and/or to enable a community to restore or even transform after the crisis (Elmqvist et al. 2019).

To our best knowledge, the emergence of urban CRIs during the COVID-19 pandemic is not reported on, nor is much known on how urban CRIs emerge in general, except for some international organisation guidelines (Oxfam 2020; IIED 2020). Two elements seem to be decisive in contexts of natural disasters (Hawkins and Maurer 2009) and health crises (Poortinga 2012). On the one hand, the social capital available within the community can dynamise the available resources of individuals and communities when facing a shock. On the other hand, the broader governance context within which the initiative is conceived represents either a catalyst or a restraint for CRIs (Creamer 2015; Lebel et al. 2006). Literature provides some insight into how local initiatives emerge (De Moor 2013; Greiner 1989), but we still lack clear insights in how CRIs emerge within various governance contexts.

This paper, therefore, raises the following research question: How do urban CRIs emerge within different governance contexts amidst the COVID-19 pandemic? More 
specifically, we answer three sub-research questions: What are the main characteristics of CRIs emerging during COVID-19? What barriers do they perceive when they emerge? What different pathways lead to the emergence of CRIs within different governance contexts?

The main contribution of the study lies in the exploration of pathways through which CRIs emerge during COVID-19. The article first explores pathways in literature by bringing together literature on resilience, Community-Based Initiatives (CBIs) and urban governance. While CBI literature analyses the emergence of CRIs in bottom-up, self-organised processes, literature on health shocks highlights the importance of collaboration with, and leadership of, health services, international (donor) support and other actors (Alonge et al. 2019). We include literature on urban governance to better appreciate such top-down or networked pathways. We subsequently describe the research methods. As the emergence of CRIs is not yet well studied, we conduct an exploratory study. The COVID-19 pandemic is unique and uniform; it has affected close to all cities around the globe for months in a row. We signal equifinality, whereby a uniform factor can lead to a similar outcome (community resilience) by following multiple possible pathways (CRI emergence) depending on local factors and their dynamics. The study conducts an international (non-random) survey with open and closed questions, triangulated with secondary data and in-depth interviews. Study limitations include that the results cannot be generalised and that we cannot be sure whether other pathways exist. Moreover, each pathway is in this explorative search rather broadly described and needs more in-depth investigation. The article subsequently identifies pathways of CRI emergence and finally we conclude by answering the research questions and setting out a policy and research agenda.

\section{Theory}

Figure 1 outlines the conceptual framework that is used to understand the emergence of CRIs in times of the COVID-19 pandemic. Based on literature, we assume that community chrematistics, urban governance and starting conditions are potential explanatory factors. These factors are expected to interact leading to coherent pathways within which CRIs emerge. Literature of CBIs analyses how CBIs emerge in self-organised processes within local communities (De Moor 2013; Greiner 1989). At the same time, CRIs are expected to operate according to existing government practices and institutions, to reinforce current practices and, above all, to comply with current policy arrangements (Healey 1995; Tatenhove et al. 2010). Urban governance can offer a supportive and enabling environment, but may also stifle CRIs (Huitema et al. 2009). Based on governance literature, we explore whether and how CRIs are supported and may emerge out of hierarchical or network governance.

\section{CRIs: Bottom-Up Emergence}

CRIs can be understood as a branch of Community-Based Initiatives (CBIs), which aim to enable a community to cope with a shock by sustaining itself and/ 


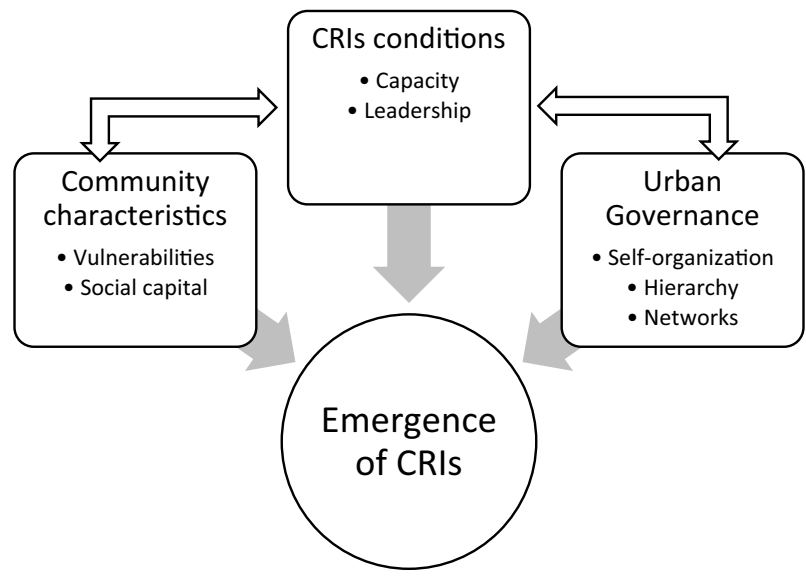

Fig. 1 Conceptual framework. Source: Authors, 2020

or transforming its trajectories (Magis 2010). A shock is likely to be a catalyst for CRIs to emerge. After the 1995 earthquake in Japan, for instance, over 180 spontaneous community initiatives emerged (Childs 2008). CRIs are a hybrid form of participation, engaged in both service and civic activities. In Arnstein's (1969) ladder of participation, they are often located at the highest level of citizen power, citizen control, meaning citizens being in full charge of a specific program or institution.

CRIs, just as CBIs, are expected to start informally in an ad-hoc manner. In their early stages, the initiatives are small with few members who work in close contact with few rules and procedures. While many CRIs are likely to disappear once the crisis is over, a few may mature leading to more complex stages of organisational development (Greiner 1989). They create an internal culture, sets of rules and procedures; a process which may end up in the creation of the future public institutions (De Moor 2013). Formal CRIs have more legitimacy and internal cohesion, with strong bonding ties among members of the core group, leadership, networks and organisational complexity. The latter relates to a larger size of the initiative, multiple resources, larger scale of intervention, more target group(s) and a broader scope (Bailey 2012; Igalla et al. 2019).

\section{Community Characteristics}

The emergence of CRIs is indicative of a resilient community (Magis 2010). In a resilient community, CRIs spontaneously emerge or adapt when a shock happens and may disappear when the crisis is over. The factors leading to community resilience are thus likely to be the factors leading to the bottom-up emergence of CRIs as well. We focus on two factors: vulnerabilities and social capital. 


\section{Vulnerabilities}

CRIs emerge in response to vulnerable situations. Vulnerabilities during the COVID-19 pandemic relate to health and socio-economic consequences of the pandemic, whereby people are vulnerable to illness possibly without health insurance (Kenny 2020), the loss of work and income (Irlacher and Koch 2020), (domestic) violence and/or social isolation (Nicola et al. 2020). The emergence of CRIs is enabled by increased community cohesion as the community faces a common threat, but it is simultaneously constraint by the depletion of community and household resources, as people lose income and may spend more money on health care (Alonge et al. 2019).

Communities can only address vulnerabilities on which they have agency, whereby the focus is likely to be on immediate and urgent contention, prevention and adaption. Poortinga (2012) found that deprived neighbourhoods consistently report lower levels of social capital, which reduces their agency. During the Ebola outbreak in Liberia, participants felt agency to mitigate the risk of the virus. They found ways to reduce EVD risks and employ preventative measures by informing communities and changing age-old routines such as burial practices, touching and handshaking (Alonge et al. 2019).

\section{Social Capital}

Social capital comprises the 'features of social life-networks, norms and trustthat enable participants to act together more effectively to pursue shared objectives' (Putnam 1995: 664-665). It facilitates the agency of CRIs, as it enables the mobilisation of resources and the coordination of local action (Hawkins and Mauer 2009). CRIs rely on social capital because they often depend on voluntary community contributions (Newman et al. 2008). The networks include community leaders, formal and informal groups and active citizens, whom interact, establish trust and create a basis of joint action.

The three forms of social capital—bonding, bridging and linking-are expected to lead to different pathways within which CRIs emerge (Poortinga 2012; Szreter and Woolcock 2004). Bonding is associated with self-organised pathways, facilitated by leadership, cohesion, kinship and trusted communication channels (Alonge et al. 2019; Poortinga 2012). At the same time, communities also bridge with and link to actors outside the community to discuss, learn and acquire resources. Poortinga (2012) argues that research focuses on bonding, which obscures alternative pathways within which CRIs emerge.

\section{Urban Governance}

CRIs do not take place in institutional isolation, they are embedded in public, private and societal environments (Tatenhove et al. 2010), which is often coined as urban governance (Peters and Pierre 2012). This environment comprises actors and 
institutions inside and outside the community. Government and especially health services is likely to be an important player during a pandemic, because many CRIs operate in the public domain and relate to institutionalised processes of service delivery, policy and/or decision-making (Brandsen et al. 2017). NGO's, firms and universities also play a role in emergency relief (Alonge et al. 2019).

Scholars have developed an abundance of classifications of urban governance. We adopt Williamson's (1991) classification into (1) self-organisation and markets; (2) hierarchy, whereby decisions that influence urban communities are made topdown and (3) networks, whereby vulnerabilities and their potential solutions are discussed and pursued by collaborative networks of interdependent public and private actors and citizens. We now discuss these three modes of governance.

\section{Self-organised CRIs}

Self-organised CRIs are bottom-up initiatives emerging from bonding capital within the community. They may receive various levels of recognition and support from the government and other actors, which may ease or restrain their emergence. The emergence of CRIs may benefit from the governments' recognition of their right to organise (Ostrom 2005) as well as from (implicit) support mechanisms, ranging from tolerating and encouraging citizen initiatives to facilitation, cooperation and providing training and resources (Bailey 2012). During a health crisis they may offer prevention programmes, community work, social corporate responsibility and various forms of health support (Alonge et al. 2019), alongside social economic support.

Negative effects arise if external actors consider CRIs as threats or if failing governments 'delegate' responsibilities into the hands of communities, under the pretext of community empowerment and self-management (MacKinnon and Derickson 2013). On the other extreme, they may also arise if external actors become overactive and do not work collaboratively but instead take over (Gonzales 2010). Support in the form of funding can negatively influence CRIs, because of misaligned timeframes, bureaucracy (red tape) and local competition (Creamer 2015). Mistrust possibly exacerbated by weak governance, corruption and weak community leadership, may render governance support as ineffective (Alonge et al. 2019). Thus, external intervention comes with a price tag, with red tape and exhaustion being examples of negative side-effects that can impede the emergence of CRIs.

\section{Hierarchical Governance}

In top-down modes of governance, the emergence of CRIs depends on the initiative and leadership of external actors. Hierarchy may be attractive during a health pandemic because coordination is efficient, response is swift and work is focused on getting things done as soon as possible. It enables a quick organisation of vital community services. Alonga et al. (2019) mention a successful example where health services engage community health volunteers in surveillance, messaging and quarantine activities during the Ebola pandemic. Chang (2013) describes how the Chinese party-state engages local residential committees in social service delivery to tackle social problems resulting from rapid socio-economic change. The risk 
of top-down approaches is however that urban managers and planners do not have enough information during a pandemic. Such top-down approaches are furthermore unlikely to increase the level of community participation and empowerment. While discouraged, self-organised CRIs may still emerge in a hierarchical system. In China, for instance, self-organised CRIs emerge within the limited spectra defined by the governments (Chan 2013).

\section{Network Governance}

In network governance, multiple actors collaborate on equal footing in support of vulnerable urban communities, thereby enabling communities to deal with uncertain situations and wicked problems (Adger et al. 2009). The networks discuss developmental choices and initiate CRIs (Folke 2006; Huitema et al. 2009). It enables quick, legitimate and flexible adaptations to emerging situations (Bruner et al. 2005; Lebel et al. 2006; Varda 2011). Michener et al. (2020) and Heimer et al. (2020), for instance, report on multiple initiatives in the USA in response to COVID-19, SARS and Aids which arise out of networks.

\section{Wrap Up}

CRIs are the (temporary) expressions of a resilient community within a supportive or restraining governance context. The interaction of community characteristics, capacities of CRIs and governance is likely to lead to multiple pathways within which CRIs emerge. Literature on CBOs discusses self-organised processes, most likely starting off informally and spontaneous. These initiatives may receive various levels of support or hindrance within the wider urban governance context. However, governance literature and experiences from previous (health) crises show that not all CRIs emerge from below. We identify networked and hierarchical pathways within which CRIs emerge. However, the evidence is sketchy and anecdotal, often banking on a few case studies and literature nor related to resilience.

\section{Methods}

The study explores the pathways within which CRIs emerge in the initial stage of the CIVID-19 pandemic. We conduct an international survey of CRIs, supplemented by in-depth interviews with experts and secondary data on urban CRIs, including searching websites of the CRIs. The unit of analysis are the CRIs. The survey combines open and closed questions to describe the emergence of CRIs and the factors leading to it. First, we distributed a self-administered online questionnaire among our network of 40,000 urban professionals. To complement these efforts and given the difficulty in gathering responses, we relied on computer-assisted interviews for global outreach as well as interviews conducted by community researchers. This ultimately resulted in 90 responses (unit of analysis) operating in 42 cities in 32 countries. As we aim for detailed feedback on the emergence of CRIs in an unknown 
situation, the questionnaires included open questions. This resulted in detailed information, but also in a relatively small sample and high non-response rate. Due to our non-random sampling strategy, we provide only descriptive statistics which offer a general picture of CRIs. In order to improve internal validity, we added seven semistructured interviews with key experts of universities and local government (in some cases with groups of experts) and a literature and website survey of articles and websites. However, external validity is low due to the sampling method.

We group CRIs using a fuzzy set analysis. In first instance, we identified three groups based on theory (bottom-up, hierarchy and network). However, the data revealed a large variety within bottom-up CRIs. We subsequently tried out different ways to group the data, achieving the best results by splitting up bottom-up initiatives in spontaneous and pre-existing CRIs. This builds on the anticipated evolution of CBIs, whereby mature CBIs have more capacity and networks to undertake activities (Greiner 1989). The four pathways (Table 1) are identified based on differences in main stakeholders (within or outside the community), leadership styles (community leader, group decisions or hierarchical leadership) and the level of formality of an initiative (formally organised versus informal and spontaneous). We anticipated the scoring of indicators for the four pathways based on theory (truth table), whereby various scores are not yet known (Table 2). After the CRIs were grouped, the research team calibrated and triangulated qualitative and quantitative data, after which the different pathways were compared among themselves and with theory.

\section{Findings}

\section{Comparing Pathways}

The four pathways described in the method section range from 20 to 24 CRIs each (Fig. 2). This section compares the pathways, after which each is described in greater detail.

The factors leading to the emergence of CRIs differ significantly (Table 3). The pathways are determined based on differences in the initiator and main stakeholder, whether the initiatives are formal or not and whether the CRI has one leader, whom possibly decides alone, or not. If the initiator is the community, the

Table 1 Pathways

\begin{tabular}{llll}
\hline Categories & Main stakeholder(s) & Leadership & Level of formality \\
\hline $\begin{array}{l}\text { 1. Bottom-up informal } \\
\text { pathways }\end{array}$ & $\begin{array}{c}\text { Community, community } \\
\text { member }\end{array}$ & $\begin{array}{c}\text { Community leader or } \\
\text { group }\end{array}$ & Informal \\
$\begin{array}{c}\text { 2. Bottom-up formal } \\
\text { pathways }\end{array}$ & $\begin{array}{c}\text { Community, community } \\
\text { member }\end{array}$ & $\begin{array}{c}\text { Community leader or } \\
\text { group }\end{array}$ & Formal \\
3. Hierarchic initiatives & One external stakeholder & Hierarchical leadership & Formal/Informal \\
4. Networked initiatives & More external stakeholders & Group leadership & Formal/Informal \\
\hline
\end{tabular}

Source: Authors, 2020 


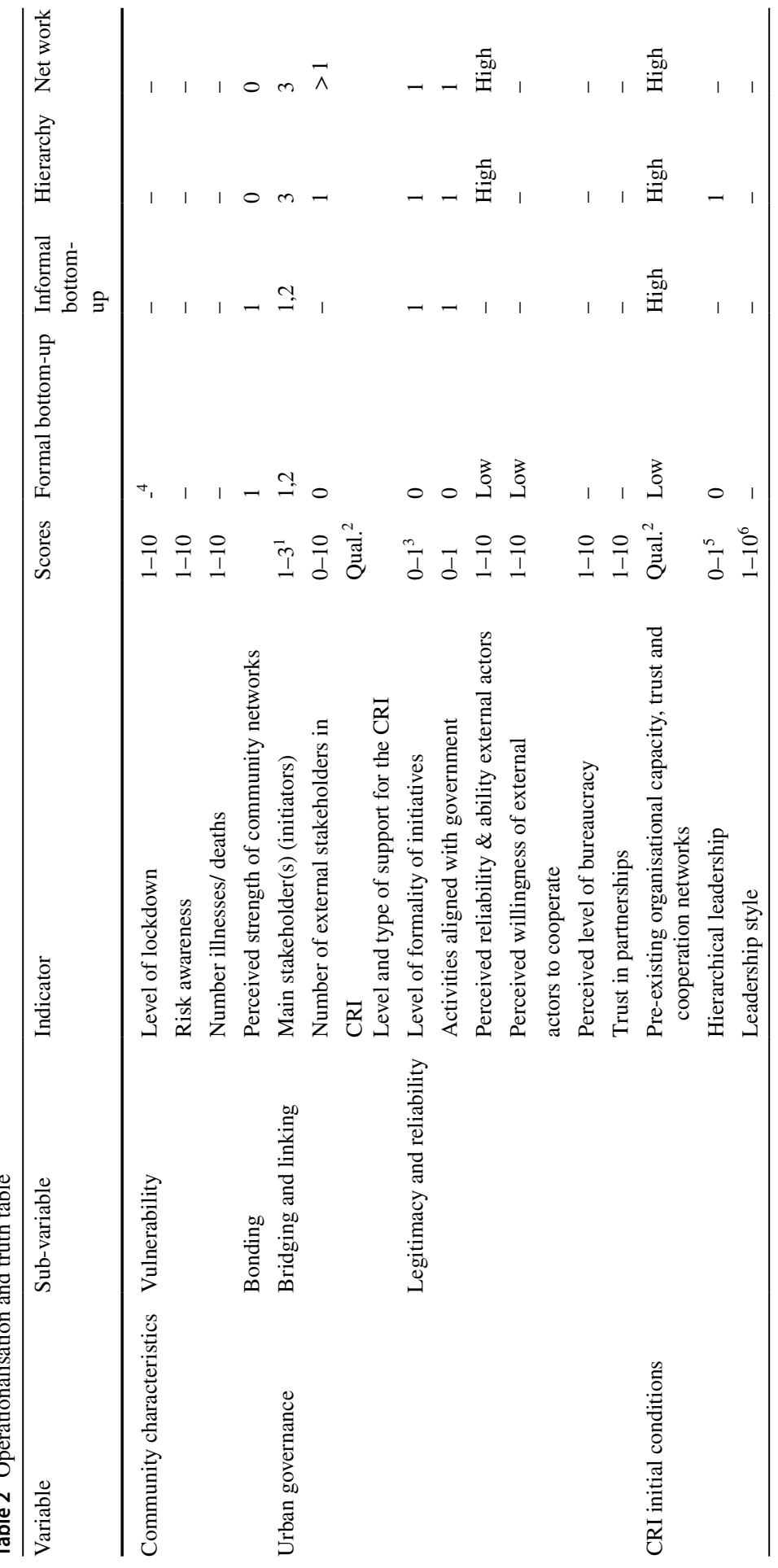

站。 


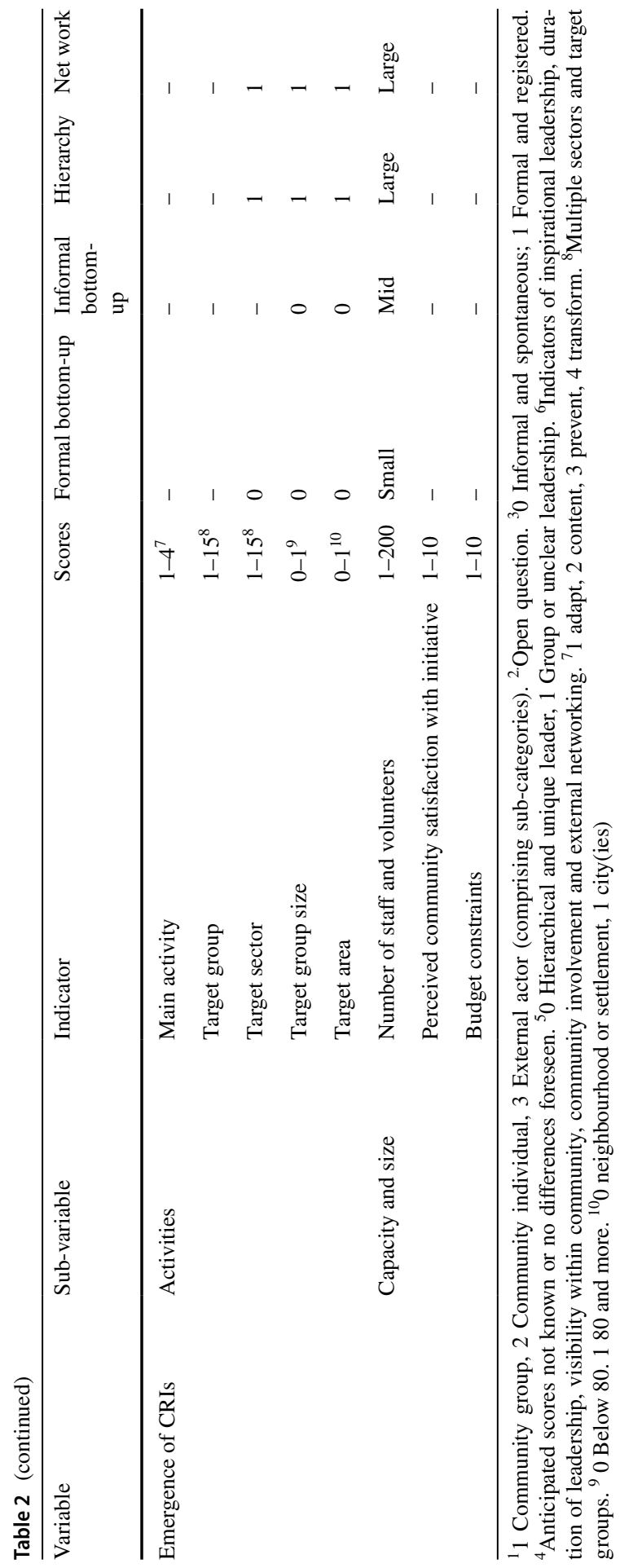




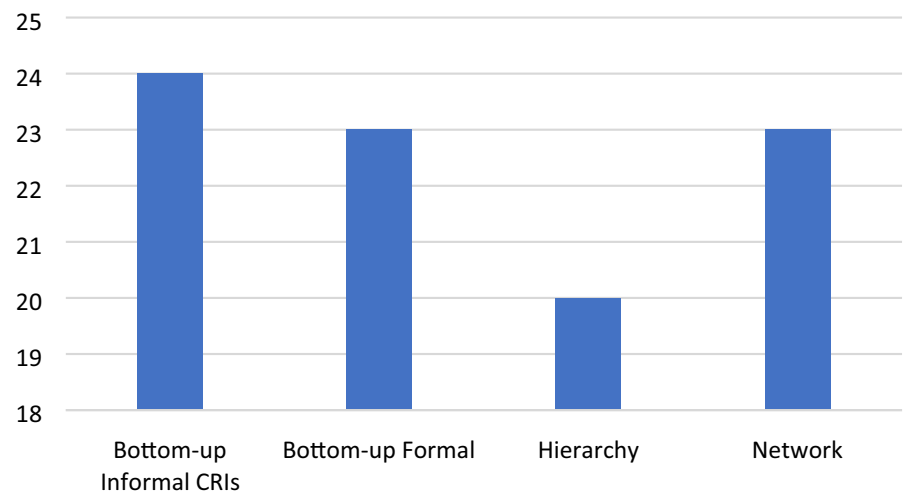

Fig. 2 Pathways (number of CRIs). Source: authors

initiative may be an informal and spontaneous activity of (a group of) residents or an initiative of an existing formal CBI. Leadership of informal bottom-up initiatives is likely to be spontaneous, with different people involved in different activities, while formal bottom-up initiatives and hierarchical initiatives are likely to be led by one leader with a formal decision-making structure. In those cases, the leader(s) manage(s) the staff and community volunteers and maintain(s) the network. Almost half of the initiatives of external actors and especially of universities, NGOs and firms are perceived to be informal, because they are outside the scope and mission of the organisation. A network offers a variety of leadership, whereby most respondents state they are unsure of decision-making processes. Informal bottom-up CRIs are also less likely to align to government policies and programmes than other initiatives, as they primarily respond to vulnerabilities of vulnerable groups.

The four pathways lead to differences in target group, activities and complexity of operations (Table 3). Bottom-up informal and hierarchical initiatives are more likely to work across a city, while bottom-up formal and networked initiatives are more likely to focus on one neighbourhood. Qualitative data reveal that the first are also more likely to focus on a specific target group and that the latter groups benefit from knowledge and network volunteers across target groups within a settlement. We also find significant differences in the type of activity. Bottom-up informal CRIs are more likely to support communities to adapt, whereas other CRIs are more likely to content and prevent the crisis. Informal bottom-up CRIs are less likely to use complex technologies. Networks deal with most actors, increasing organisational complexity. Respondents finally perceive that bottom-up initiatives are significantly more likely to satisfy communities.

There are also similarities between pathways (Table 3). CRIs report similar vulnerabilities and perceive to be held back by similar barriers: lack of funding, government bureaucracy, unwillingness, lack of capacity of governments and weak proactiveness of their network are found in all pathways. Study findings show that the number of staff ranges from 1 to 200 does not differ significantly between the four 


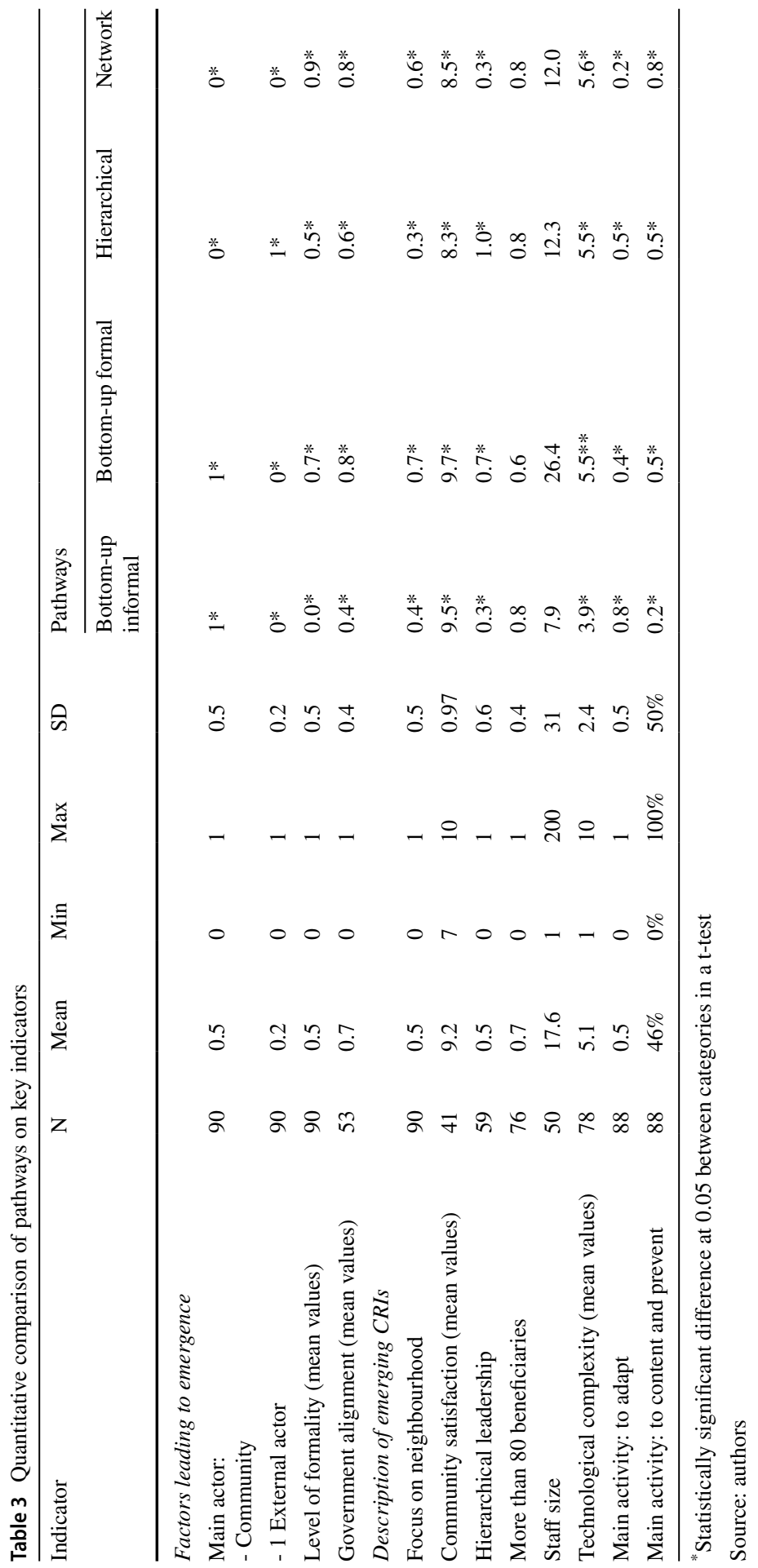


categories because of large differences within each pathway. Most CRIs cater for more than 80 beneficiaries.

The remainder of this section describes each pathway in greater detail.

\section{Bottom-Up Informal Pathways}

Informal initiatives started in between March and April 2020 most likely to adapt to the hardships of the lockdown. Poor and informal workers are priority target groups for, respectively, $79 \%$ and $63 \%$ of the respondents, while others target students and kids ( $\mathrm{R} 1,48,72)$, traders ( $\mathrm{R} 45)$ and surrounding rural communities ( $\mathrm{R}$ 15). Respondents distribute food ( $\mathrm{R} 34,37,75)$, sanitary products ( $\mathrm{R} 11,54,77)$, raise awareness ( $\mathrm{R} 5,57)$ and/or address the rise of criminality and gender violence (R 67, 54). Respondents note that communities are risk-informed, but the provision of information and response awareness are often incomplete. Sanitary products are available but in short supply and when community members can access sanitary products, their financial capacity does not ensure continuity.

Many initiatives emerge in low-income settlements, often characterised by high densities, insufficient public and private space and sometimes unsafe drinking water and inadequate sanitation. Following COVID-19 measures is perceived to be difficult, if not impossible (Friesen et al. 2020).

The emergence of bottom-up CRIs is linked to social networks within the community (Morgner et al. 2020), often also linked to existing CBIs. In some cases, new and existing initiatives crate informal temporary networks to help community members. In Kenya, an individual initiative brought three CBOs together to:

utilise skills, strengths, and stories to engage individuals with different capabilities to build sustainable change while providing 18 families [...] with food relief for three months' (R. 45).

In Italy, individuals work with CBIs to distribute food and hygiene products ( $\mathrm{R}$. 37, 38). Each participating organisation contributes expertise and networks to diversify the relief response, and community engagement is reported as high. Within these networks, leadership is spontaneous and shared among a group of people.

In Colombia, informal community initiatives came together to raise funds. They are:

committed to a heterarchical structure, in which its members act autonomously and responsibly, and where relationships are continuously transformed. Decisions that affect the collective as a whole are made in assembly and consensus, while operational decisions and decisions in the territory are made individually or in small working groups (R.15).

The role of government support during the pandemic is controversial. Local government has established online portals to share information, food hand-outs and systems for distribution of masks and sanitisers, often through NGOs already well-connected in communities. However, $87 \%$ of our bottom-up informal CRIs respondents rank government reliability, capacity, community engagement and willingness to 
cooperate with CRIs as very low. None have received government funding, instead they act on filling a gap:

It covers the lack of information on critical services that governments have not provided in the middle of the quarantine ( $\mathrm{R} 4)$.

The emerging CRIs vary in size from 5 to 30 staff members. They focus on emergency relief and therefore foresee a duration linked to the duration of the pandemic. Other characteristics are that they have weak links with government, low financial availability and limited technical, legal and organisational complexity, unless they work in (temporary) networks. The main reported bottlenecks are funding shortages for $70 \%$ of this type of CRIs and fragmented networks and partner's disengagement for $33 \%$, threating the continuity of activities, as in the case of R. 74 in Mexico:

We lack a lot of exposure. [...] At the same time, we lack a lot of resources and the demand for help is extremely high. [...] The team is disintegrating. All the projects we have are going to be closed and we are just going to be working in what we do best: linking the demand with the offer of help (R. 74).

\section{Bottom-Up Formal Pathways}

CRIs which emerge out of existing community-based initiatives benefit from (1) deep (tacit) knowledge of (a) specific target group(s) and/or neighbourhood, (2) a skillset, (3) the existing organisational capacity and (4) existing networks. This gives them a head start.

Most pre-existing CBIs target vulnerable people. For instance, respondent 31 in Guyana offers specialised mental support for migrants. As most migrants lost their jobs due to the pandemic, they started offering food and basic services. Respondent 43 in Nairobi has a very specific target group: it works with youth in a football club in an informal settlement. During the pandemic, they start offering awareness raising on social distancing and hygiene. The target group thus informs the CBI of COVID-19-related vulnerabilities, and the CBI subsequently offers targeted resilience initiatives.

The targeted vulnerable groups are often difficult to reach. Their local networks and tacit knowledge enable them to reach out. Respondent 53, for instance, supports about 200 teenage mothers with saving schemes, loans, training and support to start a small business. During the lock-down, they support starting businesses to deal with the pandemic. Various CBIs are working with youth gangs and/or unemployed youngsters in order to combat crime. CRIs engage in reporting cases of violence ( $R$ 47), creating a local art hub (R 62), organising (sport) activities in order to engage the youth ( $\mathrm{R}$ 62) or employing youth to distribute food, masks and sanitisers ( $\mathrm{R} 51$, 60).

A few CRIs follow an area-based approach: they first identify specific vulnerable groups in surveys, then lobby for assistance to this vulnerable groups of people, and/or provide food, information and a wide variety of other services to cope with COVID-19. They benefit from a network of volunteers and financial support of an NGO (R. 3, 4, 44, 50). As respondent 3 notes: 
[Our organization] is consistently working in this locality for the last five years as a non-political social welfare organization. So when pandemic started, we felt our responsibility to work for the community especially those who are affected by this situation anyways.

A second factor influencing the emergence of CRIs is the skillset of CBIs, such as counselling, conducting surveys or offering microfinance. Respondents 44, 56 and 83 are specialised in community mapping, which enables them to map vulnerabilities within the local communities. Their community volunteers are trained as mappers or community researchers. Respondent 44 notes:

When COVID-19 hit our country and cases began to rise the team members decided to focus all their efforts to help the community to identify the gaps (vulnerabilities) with facts.

With a focus on food, water and COVID-19 prevention, the CRI identified 587 households that were extremely vulnerable, including single young mothers, elderly and food-insecure households. They now among others supply food for 87 household and lobby for more support.

Existing CBIs also make a head start due to existing leadership and organisational capacities. Respondent 4 notes:

We as an organization had to do many things to fight the pandemic. We have enough volunteers and goodwill in this locality (...). Our organizational arrangements helped a lot to take immediate initiatives.

Community leaders motivate volunteers and attain technical and financial support (R. 51). This also enables moving to scale. It enables respondent 58 to install 221 hand washing and information points staffed by volunteers and to distribute 3,255 food packages, 400,000 bars of soap and 256,471 hand sanitisers and direct cash transfers of $\$ 30$ USD equivalent per month for three months to vulnerable families.

The networks of the leaders also enable CRIs to scale activities during the pandemic. The most frequent networks are with other CRIs, NGOs and donor organisations. For respondent 64, donors pay the cleaners fee during the pandemic in order to create employment for the youths and clean the neighbourhood. Some CRIs receive support from firms (R. 59, 66 and 70). Most CRIs align their activities to government policies and about half receive support in the form of training, information or promotion. Respondent 31 connects migrants to local government for employment and housing support.

Networking may lead to temporary networks. Respondent 35, 49 and 70 report of local networking of CRIs, which enable them to bundle resources. Respondent 35 offers a network of committee representatives, NGO representatives, and slum dwellers set up in 2008, which includes ward and area committees, Resident Welfare Associations, issue-based collectives and associations of women, migrants and sex workers. The network of CRIs enables. 
a holistic approach (...) to balance out the impacts and remedies for the situation created due to COVID-19; enabling the local citizens as well as vulnerable groups to sustain the complex dynamics with nature (R. 35).

Similarly, respondent 49 reports how organisations come together to organise a virtual festival in support of 500 small businesses run by vulnerable women. Networking can lead towards a situation akin of hierarchical governance. Respondent 59 and 66 both support digital apps and platforms as social corporate responsibility of large firms to enable underprivileged youth to learn and equip with technical and business skills.

\section{Hierarchical Pathways}

External actors initiating CRIs include universities or research institutions (25\%), the government at national $(20 \%)$ or local $(15 \%)$ level, NGOs $(15 \%)$ and the private sector (10\%). This pathway is characterised by an asymmetrical relationship among the stakeholders, with leadership and resources concentrated in the external actor and community members working as volunteers. Respondents note a low level of bonding. The CRIs instead benefit from linking social capital. The hierarchical structure may sometimes resemble a network structure, because $50 \%$ adopt participatory decision-making structures.

In 55\% of all CRIs, the external actor has institutionalised community development. For instance: "We have a philosophy inspired by a Bantu proverb "Ubuntu" which means (...): I am open and available for others' (R. 17). The expertise and resources of the institution determine the scale of intervention of the initiative. There is an inclination for acting on the long-term adaptation to the effects of the crisis $(47 \%)$ as well as on prevention and contention (26\%). A wide variety of actions are included here, from the creation of booklets and didactic/informative material ( R 20, $17,29)$ to public policy insights ( 8 ), advocacy (R 71) and reports of the first stage impacts of the crisis ( $\mathrm{R} 9$ ). The number of initiatives that have been dedicated to immediate relief $(\mathrm{R} 13,34)$ is therefore modest.

$45 \%$ of the respondents identify their initiative as informal because they operate outside the institutional mandate. The actions are instead initiated by groups or individuals within the institution. Respondent 13 reports of a voluntary initiative within a university:

When the pandemic was officially declared on 15 March, our volunteering programme stopped working in its normal mode as well (...). For two weeks we re-evaluated ourselves and asked what we could do there? (...). We started to see that people started putting red scarfs on their windows to show that they had nothing to eat. We saw the need and began to seek advice from other organisations that have worked in immediate relief (...). At first, we thought about going out on our own, in a personal way, without the university (...) but then we decided to talk to the university to see if there was institutional cooperation. 
External actors may offer their 'normal' services to communities or adapt services. Research centres ( $\mathrm{R} 2,8,9)$ offer their usual institutional support to urban communities:

The Observatory is a broker of scientific knowledge that informs thinking and decision-making about inequalities in income, opportunity and quality of life [therefore we] ensure that the issue of inequalities remains on the agenda, in particular inequalities linked to the pandemic (R.8).

Interviewees in Shanghai and Wuhan informed us that the Chinese government has institutionalised hierarchical CRIs since a National Emergency Management structure was established after the SARS outbreak in 2013. The structure enables quick and decisive government action based on emergency plans across municipal departments and government levels. The response is staggered, cutting the contagion chain at three main levels, from individual-infected people to community and highrisk areas, defining precautionary measures for each. This institutionalised structure is applied during the COVID-19 outbreak as well. In Shanghai and Wuhan, neighbourhood committees oversee taking the temperature of the people at the entrance of each residential compartment as well as providing support services, such as driving people to hospitals, providing food and arranging volunteers (den Hartog 2020). The spatial structure of neighbourhoods, with a limited number of entrances, and the neighbourhood committees enable a decentralised health control system. The Chinese neighbourhood committees enable active residents to contribute to public health but can also be perceived as an intrusion on individual liberties. Audin (2015) refers to the structure as participative bureaucratisation.

\section{Networked Pathways}

Horizontal coordination may lead to the emergence of CRIs as well. Networks are especially triggered by food and income insecurity and weak health infrastructure. Respondent 86, in the Philippines, for instance offers national and local networks to create employment and services in metropolitan regions other than the overcrowded Metropolitan Area of Manila. There is variety in the outreach of networks, whereby a few networks have a very large outreach: respondent 19 reaches out to 15,680 people for food and sanitary products in Dominique republic, and respondent 14 offers a network spanning across 158 municipalities to offer food and sanitary relief in Colombia.

Networked CRIs are able deal with the complexity of diverse stakeholders (7.3 out of 10), target groups and funding agencies ( 6.7 out of 10) by bundling resources. However, the networks are vulnerable to a break in trust (R. 84, 90), with 34\% report that partners are disengaging. About half of the networks report a lack of funding $(52 \%)$.

Most networks align with and receive in-kind support of the government:

We are working in alignment and close coordination with local and national government stakeholders that have expertise in outbreak response protocols and referral procedures (R. 67). 
However, only two networks (R. 87, 89) have received financial government support. Moreover, respondents perceived government willingness and capacity to networks and to include communities in their decision-making as very low. Nevertheless, the government is seen as a key stakeholder and networks therefore aim to inform or lobby with the government:

[our] objectives are both from a perspective of organisational strengthening and social transformation. They are also set in a context where the government will need evidence to adapt the measures in its next government action plan for community action to the real needs of organizations [after Covid] (R. 9.).

Lima, Peru (R 84) is the only network initiated by government: the mayor reactivated a dormant network of neighbourhood councils, enabling $460 \mathrm{CBI}$ to join a government campaign to prevent the spread of COVID-19. The reach of the initiative is limited to the city centre, because of restrictions in the jurisdiction and weak collaboration among government levels.

Networks have a tendency towards hierarchy, especially when institutions external to communities lead the network. Communities may be perceived as beneficiaries rather than agents, with relatively low level of participation and community empowerment. In South Africa, respondent 87 is for instance critical of the network's decision-making structure and argues that homeless community should form part of the steering committee.

\section{Discussion}

The theory section has identified three pathways within which CRIs emerge: selforganised, hierarchical and networked. Our study findings confirm these pathways and find that these constitute, respectively, 52\%, 22\% and $26 \%$ of the non-random sample. The study adds two issues to theory. First, the analysed identified a fourth pathway by splitting self-organised CRIs into informal and formal initiatives. They have a similar size in the sample but differ significantly in both the way they emerge and characteristics. Second, we add a deeper description of factors leading to CRIs and resulting activities for each pathway. Of particular relevance is that in all pathways the CRIs perceive barriers related to governance factors, such as willingness to cooperate and financial support received. This will be taken up in the conclusions. We now discuss the pathways, highlighting additions to theory.

The first pathway resembles the initial phase of CBI development (Greiner 1989), with most likely spontaneous leadership, low technological complexity and initiatives not aligned with government programmes. Individuals within a community establish an informal CRI in direct response to a vulnerability. We find that such activities often focus on a target group such as migrants or youth and not necessarily a neighbourhood. The initiative is likely to support the target group to adapt to the crisis. The study confirms that informal CRIs may emerge out of bonding networks within communities and often in cooperation with existing CBIs (McCrea et al. 2014; Putnam 1995; Bailey 2012). This results in temporary networks of actors supporting a vulnerable group or neighbourhood. Greiner (1989) argues that informal 
and small CBIs may ultimately grow into formal and large CBIs, but in this study CRIs perceive their initiatives as temporary.

A second pathway is that CRIs emerge out of existing CBIs, whereby resilience initiatives benefit from existing knowledge of neighbourhoods and target groups, organisational capacity and leadership, skills and networks (Greiner 1989). These CBI's already have formal recognition, organisational capacity and bonding, bridging and linking networks (Putnam 1995). This allows them to handle a larger number and greater complexity of partners, target groups, activities and funding sources than the previously mentioned informal CRIs (see also Bailey 2012). Respondents expect community satisfaction to be higher for both forms of bottom-up initiatives than hierarchical and network initiatives.

A third pathway, which is not often studied, is that of CRIs hierarchically initiated by governments, NGOs or universities. These external actors are institutionalised and capacitated, connecting to a community due to previous or ongoing activities, mandates or staff (or student) linkages. Such linking social capital connects external knowledge and resources to communities, potentially enabling initiatives of a larger scale and complexity. This pathway associates with hierarchical governance (Edelenbos and van Meerkerk 2016; MacKinnon and Derickson 2013). Study results show a wide variety in outreach, ranging from relatively small voluntary initiatives of a university to institutionalised hierarchical CRIs throughout China, where local governments actively neighbourhood committees in resilience activities (Audin 2015; Den Hartog 2020). This pathway is likely to lead to lower levels of participation and possibly even to tokenism and manipulation as there are many conditions and rules set to the way and to what extent engagement can take place (Arnstein 1969). Paraphrasing Healey (1995), hierarchical governance can be an effective mode of governance for short-term recovery, but it is less effective in dealing with long-term wicked transformations as it needs more and continued collaborative efforts of the many stakeholders involved.

The fourth pathway comprises CRIs initiated by a horizontal network of actors resembling adaptive polycentric governance (Adger et al. 2009; Brunner et al. 2005). We find multiple examples of horizontal networking among NGOs, CRIs, community members and associations, bundling resources to target multiple vulnerable groups in one or more settlements (see also Michener et al. 2020 and Heimer et al. 2020). Our study findings confirm that networks can deal with a lot of technical and organisational complexity and can increase the scope for community resilience (Brandsen et al. 2017; Lebel et al. 2006). The government is often absent or mistrusted in these networks, or its bureaucracy limits impact. This finding contradicts Klijn and Koppenjan (2016), whom argue that governments increasingly take active part in networks. By contrast, study results show that the sampled CRIs perceive governments to be unwilling and unable. The limited role of governments in networks is however problematic as many resilience activities are in the public sphere and relate to public services (see also Brandsen et al. 2017). As the leading actors of networks are often outside the vulnerable community, we also note a tendency for hierarchical decision-making, at a cost of community empowerment. 


\section{Conclusions}

This study draws light on the multiple pathways within which urban CRIs emerge within different governance contexts amidst the COVID-19 pandemic. It has answered three research questions based on an international survey of $90 \mathrm{CRIs}$, secondary data and in-depth interviews.

The first question is: What are the main characteristics of CRIs emerging during COVID-19? Study results show that CRIs are more likely to be temporary than CBIs (Greiner 1989) because they address temporary vulnerabilities arising due to the pandemic. They often align to government regulations (Healey 1995), but spontaneous CRIs are likely to focus on a target group without considering alignment. They target vulnerable groups and areas, which are difficult to reach, most likely reaching out to over 80 beneficiaries. The staff size ranges from 1 to 200 persons. The capacities and resources come from within the community in about half of the CRIs. Otherwise CRIs offer a mixed back of organisations, with different characteristics and pathways within which they emerge.

Second, the study has studied perceived barriers to the emergence of CRIs. The main perceived barriers are a lack of funding and materials, weak partnerships and weak networks. The government is often seen as unreliable and absent, uninterested in collaboration with or funding CRIs. The findings confirm that governments may 'delegate' their responsibility (MacKinnon and Derickson 2011), at least partially due to a lack of capacity to cope with the pandemic. Contrary to theory on network governance (Klijn and Koppenjan 2016), government is often absent in or unable to actively contribute to networks, partially due to bureaucracy. While scholars recommend actions to recognise and support community initiative (Alonge et al. 2019, Bailey 2012; Ostrom 2005), governments seem to offer little recognition and support to CRIs during the early stages of the COVID-19 pandemic.

Third, the study has explored pathways leading to the emergence of CRIs. Study results confirm that CBIs may emerge in self-organised bottom-up processes. We also confirm the emergence of CRIs in hierarchical and networked pathways (Brunner et al. 2005; Varda 2011) and therefore agree with Poortinga (1012) that literature on CRIs should look beyond bottom-up initiatives by paying more attention to initiatives of other actors. The study adds a fourth pathway to literature by splitting the bottom-up pathways into informal initiatives versus existing CBIs which use their resources and networks to initiate CRIs. These two bottom-up pathways differ significantly and lead to different CRI characteristics. The study also adds a deeper description of factors leading to CRIs and resulting activities for each pathway.

This exploratory study leads to a research agenda and generic policy recommendations. We strongly recommend further substantiation and validation of the pathways found, especially because the study had a small and non-random sample: Are these the most dominant pathways of CRI in times of (COVID-19) crisis? A study with a larger dataset, more cases and the inclusion of other stages of community resilience may point towards other (subsets of) pathways. In-depth 
process tracing case studies may furthermore analyse more deeply how CRIs evolve within dynamic local contexts, thereby unearthing deeper mechanisms underlying the emergence of CRIs.

The study leads to three generic policy recommendations. First, we recommend governments and other actors to support CRIs, as our respondents note a lack of resources, networks and partnerships. Our findings concur with Alonga et al. (2019) that efforts to proactively strengthen community resilience do not attract as much support, as it deserves. Second, we recommend strengthening horizontal networking with CRIs linked to support mechanisms. Establishing polycentric networks is time consuming and we therefore recommend network development in preparation of a next crisis or second or third wave of COVID-19. We also recommend a stronger role of governments in horizontal networks. Third, we recommend considering all four pathways within cities, depending on local context, in order to benefit from their different advantages and disadvantages. In times of uncertainty, it is recommended to keep development options open.

Acknowledgements Special thanks to Alexander Los, Beatrice Hati Gitundu, Jacktone Jesse Opiyo, Ashura Mciteka, Cecilia Pamparo, Dylan Clementia, Shanti Rochester, Viviana Peña, Carlos Contreras, José García, and professors Harry den Hartog, Bo Fan, Dahai Zhao, Chuanshen Qin, Xin Liang, Feng Yu for their insightful contributions.

\section{References}

Adger, W.N., S. Dessai, M. Goulden, M. Hulme, I. Lorenzoni, D.R. Nelson, L.O. Naess, J. Wolf, and A. Wreford. 2009. Are there social limits to adaptation to climate change? Climatic Change 93 (3): 335-354.

Alonge, O., S. Sonkarlay, W. Gwaikolo, C. Fahim, J.L. Cooper, and D.H. Peters. 2019. Understanding the role of community resilience in addressing the Ebola virus disease epidemic in Liberia: a qualitative study (community resilience in Liberia). Global Health Action 12 (1): 1662682.

Arnstein, S.R. 1969. A ladder of citizen participation. Journal of the American Institute of Planners 35 (4): 216-224.

Audin, J. 2015. Governing through the neighbourhood community (shequ) in China. Revue Française de Science Politique 65 (1): 85-110.

Bailey, N. 2012. The role, organisation and contribution of community enterprise to urban regeneration policy in the UK. Progress in Planning 77 (1): 1-35.

Brandsen, T., W. Trommel, and B. Verschuere. 2017. The state and the reconstruction of civil society. International Review of Administrative Sciences 83 (4): 676-693.

Brunner, R.D., T.A. Steelman, L. Coe-Juell, C.M. Cromley, C.M. Edwards, and D.W. Tucker. 2005. Adaptive Governance; Integrating Science, Policy, and Decision Making. New York: Columbia University Press.

Chan, C.K.C. 2013. Community-based organizations for migrant workers' rights: the emergence of labour NGOs in China. Community Development Journal 48 (1): 6-22.

Childs, I. 2008. Emergence of new volunteerism: Increasing community resilience to natural disasters in Japan. The Phoenix of Natural Disasters: Community Resilience: 171-180.

Creamer, E. 2015. The double-edged sword of grant funding: a study of community-led climate change initiatives in remote rural Scotland. Local Environment 20 (9): 981-999.

de Moor, A. 2013. Creativity meets rationale: collaboration patterns for social innovation. In Creativity and Rationale, ed. A. de Moor, 377-404. London: Springer.

den Hartog, H. 2020. Shanghai Na COVID-19: Global city en bouwen voor de buurt. Archined, Rotterdam. Available: https://www.archined.nl/2020/04/shanghai-na-covid-19-global-city-en-bouwe n-voor-de-buurt. Accessed 24 Sept 2020. 
Edelenbos, J., and I. van Meerkerk, eds. 2016. Critical Reflections on Interactive Governance: Selforganization and Participation in Public Governance. Cheltenham: Edward Elgar Publishing.

Elmqvist, T., E. Andersson, N. Frantzeskaki, T. McPhearson, P. Olsson, O. Gaffney, and C. Folke. 2019. Sustainability and resilience for transformation in the urban century. Nature Sustainability 2 (4): 267-273.

Folke, C. 2006. Resilience: the emergence of a perspective for socio-ecological systems analyses. Global Environmental Change 16: 253-267.

Friesen, J., V. Friesen, I. Dietrich, \& P. Pelz. 2020. Slums, space, and state of health-a link between settlement morphology and health data. International Journal of Environmental Research and Public Health 17(6): 2022.

Gonzales, V.A. 2010. A different kind of social enterprise: social cooperatives and the development of civic capital in Italy. Community Development 41 (1): 50-75.

Greiner, L.E. 1989. Evolution and revolution as organizations grow. In Readings in strategic management, 373-387. London: Palgrave.

Hawkins, R.L., and K. Maurer. 2009. Bonding, bridging and linking: how social capital operated in New Orleans following Hurricane Katrina. The British Journal of Social Work 40 (6): 1777-1793.

Healey, P. 1995. Managing cities: the new urban context. New Jersey: Wiley.

Heimer, R., R. McNeil, and D. Vlahov. 2020. A community responds to the COVID-19 pandemic: a case study in protecting the health and human rights of people who use drugs. Journal of Urban Health 97 (4): 448-456.

Huitema, D., E. Mostert, W. Egas, S. Moellenkamp, C. Pahl-Wostl, and R. Yalcin. 2009. Adaptive water governance: assessing the institutional prescriptions of adaptive (co)management from a governance perspective and defining a research agenda. Ecology and Society 14 (1): 26.

Igalla, M., J. Edelenbos, and I. van Meerkerk. 2019. Citizens in action, what do they accomplish? A systematic literature review of citizen initiatives, their main characteristics, outcomes, and factors. VOLUNTAS: International Journal of Voluntary and Nonprofit Organizations 30 (5): 1176-1194.

IIED. 2020. Emerging lessons from community-led COVID-19 responses in urban areas. https://www. iied.org/emerging-lessons-community-led-covid-19-responses-urban-areas. Accessed 1 Oct 2020.

Irlacher, M. and Koch, M. (2020) Working from Home, Wages, and Regional Inequality in the Light of COVID-19.

Kenny, S. (2020) Covid-19 and community development. Community Development Journal.

Klijn, E.H., and J. Koppenjan. 2016. The 11 Shift toward Network Governance. Theory and Practice of Public Sector Reform 27: 158.

Lebel, L., Anderies, J.M., Campbell, B., Folke, C., Hatfield-Dodds, S., Hughes, T.P. and Wilson, J. (2006) Governance and the Capacity to Manage Resilience in Regional Social-Ecological Systems. Ecology and Society 11(1).

MacKinnon, D., and K.D. Derickson. 2013. From resilience to resourcefulness: a critique of resilience policy and activism. Progress in Human Geography 37 (2): 253-270.

Magis, K. 2010. Community resilience: an indicator of social sustainability. Society and Natural Resources 23 (5): 401-416.

McCrea, R., A. Walton, and R. Leonard. 2014. A conceptual framework for investigating community wellbeing and resilience. Rural Society 23 (3): 270-282.

Michener, L., S. Aguilar-Gaxiola, P.M. Alberti, M.J. Castaneda, B.C. Castrucci, L.M. Harrison, et al. 2020. Peer reviewed: engaging with communities-lessons (re) learned from COVID-19. Preventing Chronic Disease 17: E65.

Morgner, C., A. Ambole, C. Anditi, and D. Githira. 2020. Exploring the Dynamics of Social Networks in Urban Informal Settlements: The Case of Mathare Valley. Kenya: Urban Forum.

Newman, L., L. Waldron, A. Dale, and K. Carriere. 2008. Sustainable urban community development from the grassroots: challenges and opportunities in a pedestrian street initiative. Local Environment 13 (2): 129-139.

Nicola, M., Z. Alsafi, C. Sohrabi, A. Kerwan, A. Al-Jabir, C. Iosifidis, M. Agha, and R. Agha. 2020. The socio-economic implications of the coronavirus and COVID-19 pandemic: a review. International Journal of Surgery 78: 185-193.

Ostrom, E. 2005. Understanding Institutional Diversity. New Haven, CT: Princeton University.

Oxfam. 2020. A guide for community-facing staff, https://reliefweb.int/sites/reliefweb.int/files/resources/ gd-covid-19-oxfam-community-engagement-guide-270420-en.pdf. Accessed 1 Oct 2020.

Peters, B.G., and J. Pierre. 2012. Urban governance. In: The Oxford Handbook of Urban Politics 
Poortinga, W. 2012. Community resilience and health: The role of bonding, bridging, and linking aspects of social capital. Health \& place 18 (2): 286-295.

Putnam, R.D. 1995. Tuning In, Tuning Out: The Strange Disappearance of Social Capital in America. PS: Political Science \& Politics 28 (4): 664-684.

Szreter, S., and M. Woolcock. 2004. Health by association? Social capital, social theory, and the political economy of public health. International Journal of Epidemiology 33 (4): 650-667.

Van Tatenhove, J., J. Edelenbos, and P.J. Klok. 2010. Power and interactive policy-making: a comparative study of power and influence in 8 interactive projects in The Netherlands. Public Administration 88 (3): 609-626.

Varda, D.M. 2011. A network perspective on state-society synergy to increase community- level social capital. Nonprofit and Voluntary Sector Quarterly 40 (5): 1-28.

WHO (2020) WHO Coronavirus Disease (COVID-19) Dashboard, https://covid19.who.int/. Accessed 1 Oct 2020.

Williamson, O.E. 1991. Comparative economic organization. Administrative Science Quarterly 36 (2): 269-297.

Zamboni, L.M. 2017. Theory and metrics of community resilience: a systematic literature review based on public health guidelines. Disaster medicine and public health preparedness 11 (6): 756-763.

Publisher's Note Springer Nature remains neutral with regard to jurisdictional claims in published maps and institutional affiliations.

\section{Affiliations}

\section{Jan Fransen ${ }^{1}(1) \cdot$ Daniela Ochoa Peralta $^{2} \cdot$ Francesca Vanelli $^{3}$. Jurian Edelenbos ${ }^{4} \cdot$ Beatriz Calzada Olvera ${ }^{5}$}

Daniela Ochoa Peralta

ochoaperalta@ihs.nl

Francesca Vanelli

vanelli@ihs.nl

Jurian Edelenbos

edelenbos@essb.eur.nl

Beatriz Calzada Olvera

calzadaolvera@ihs.nl

1 Urban Economic Development and Resilience, IHS Erasmus University Rotterdam, P.O. Box 1935, 3000 BX Rotterdam, The Netherlands

2 Urban and Community Resilience, IHS Erasmus University Rotterdam, P.O. Box 1935, 3000 BX Rotterdam, The Netherlands

3 Urban Land Governance for Sustainable Development, IHS Erasmus University Rotterdam, P.O. Box 1935, 3000 BX Rotterdam, The Netherlands

4 Department of Public Administration and Sociology, Erasmus School of Social and Behavioural Sciences, Erasmus University Rotterdam, P.O. Box 1738, 3000 DR Rotterdam, The Netherlands

5 IHS Erasmus University Rotterdam, P.O. Box 1935, 3000 BX Rotterdam, The Netherlands 